\title{
وجوب المراجعة كأثر للقول بوقوع الطلاق البدعي، من حيث الوقت
}

$$
\begin{aligned}
& \text { د. شرفي عبد القادر } \\
& \text { كلية الحقوق } \\
& \text { جامعة الإخوة منتوري } \\
& \text { قسنطينة }
\end{aligned}
$$

$$
\text { ملخص: }
$$

\section{مقدمة: $\quad$ Abstract:}

نستعرض في هذا المقال مذهب

جمهور الحنفية والمالكية والظاهرية في لهالي ما يتعلق بأثر القول بوقوع الطوالية والطاق

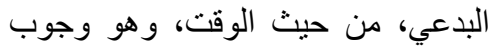
قيام المطلق بمراجعة مطلقته، وما وإذ إذاب

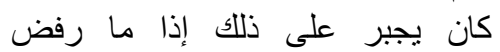

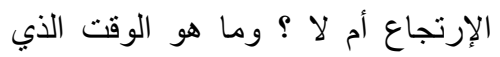

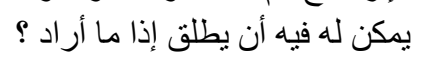

The purpose of this study is to try to find out the need to review the occurrence of divorce as a pretence in terms of time.

Therefore, the question that arises as to whether the husband can review his divorce, and whether he is forced to do so if he refuses to recuperate or not.

This is what we will try to clarify through this article. 


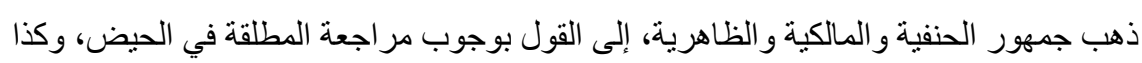

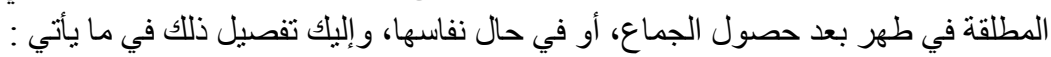

أولا : فقهاء الحنفية

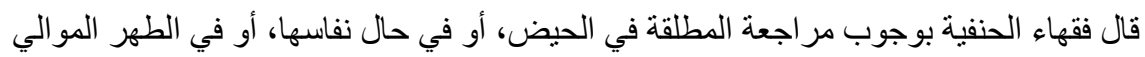

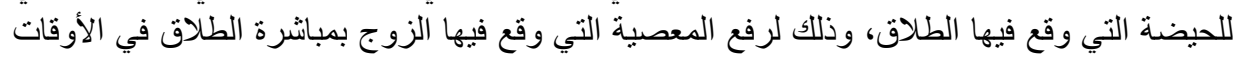

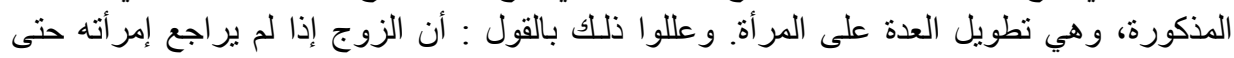
طهرت تقررت المعصية.

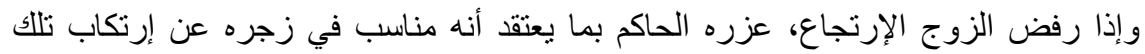

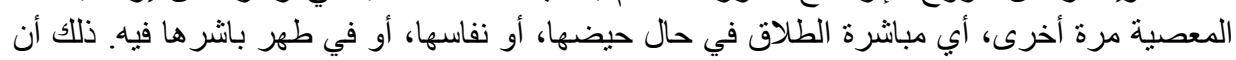

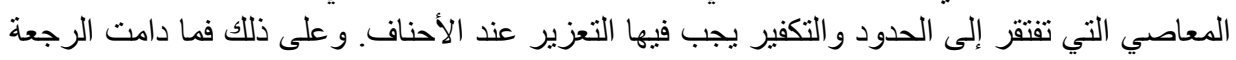

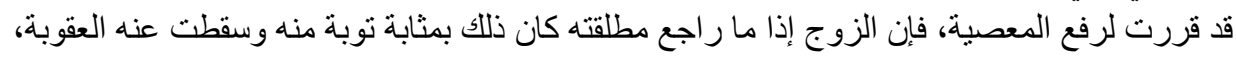
(1) و وإلا بقيت في حقه قائمة .

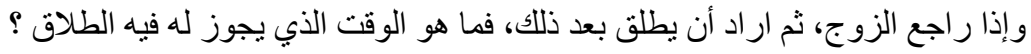

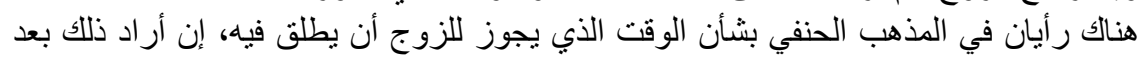

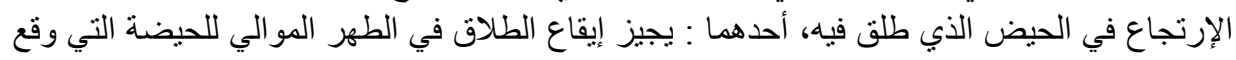

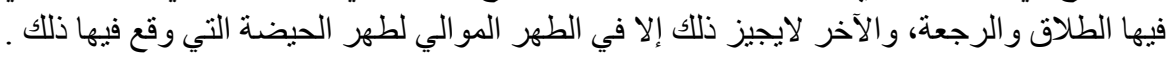

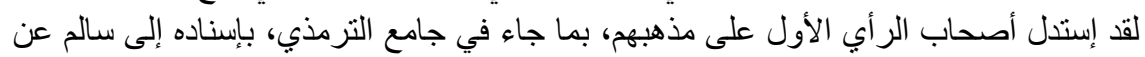

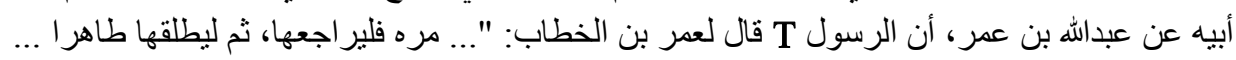

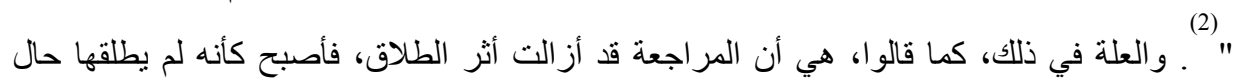

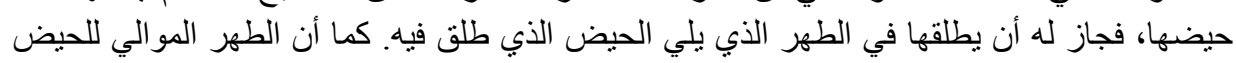

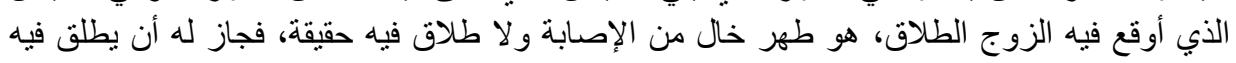

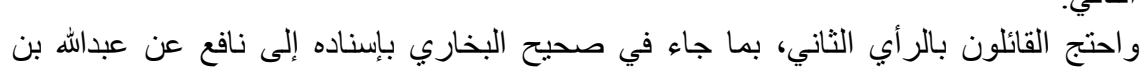

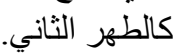

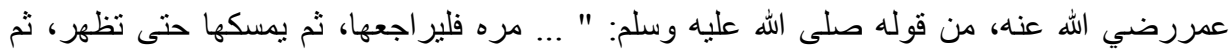
(3)

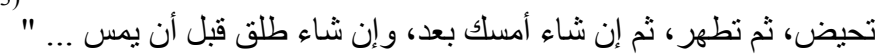

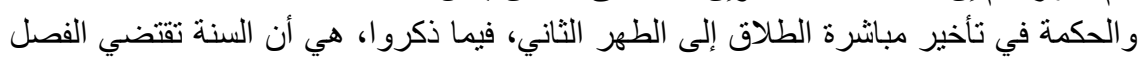

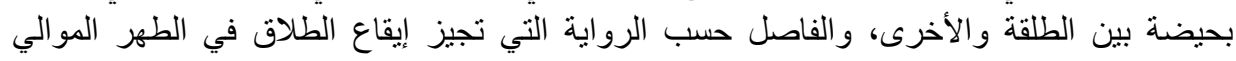

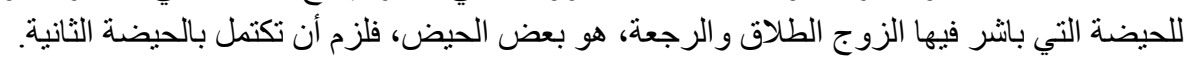

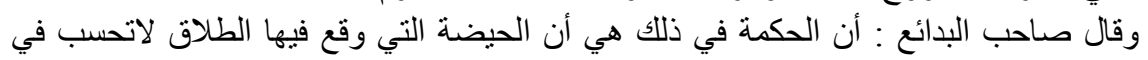

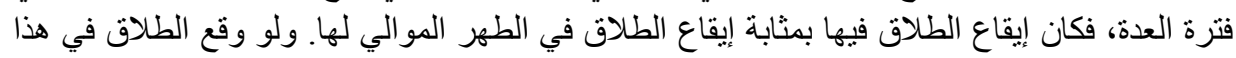

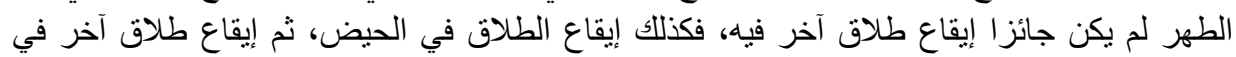

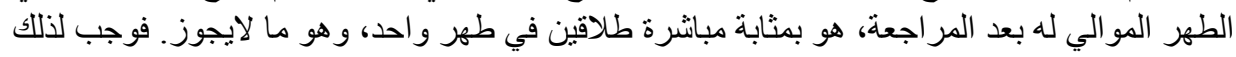

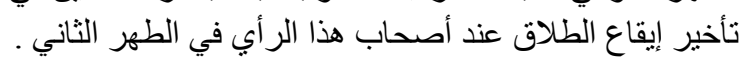

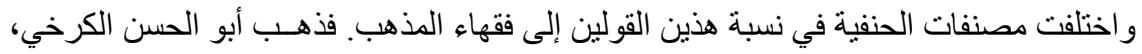

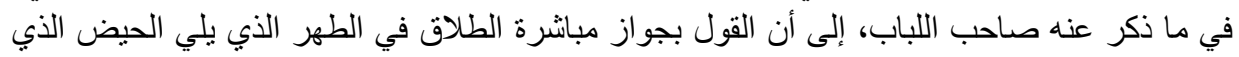


وقع فيه الطلاق والإرتجاع، هو قول أبي حنيفة. وأن القول بعدم جواز ذلك إلا في الطهر الموالي لطهر

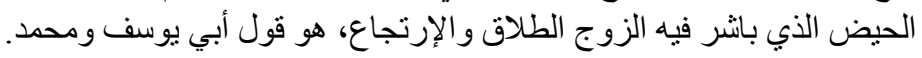

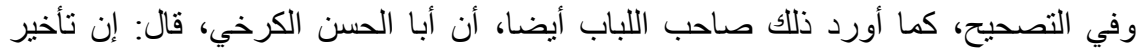

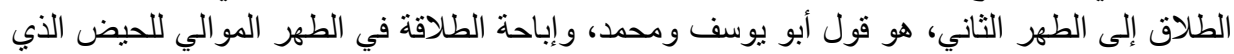
وقع فيه الطلاق و الرجعة، هو قول أبي حنيفة.

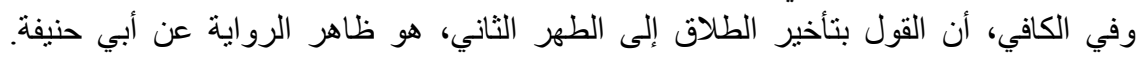

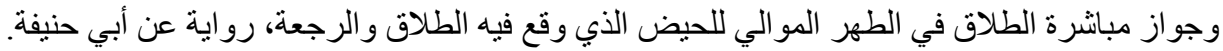

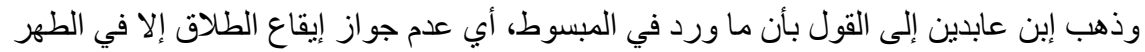

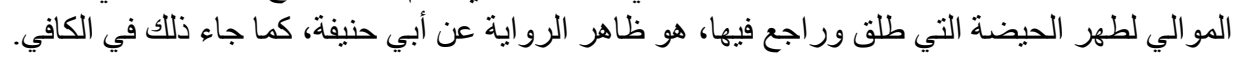

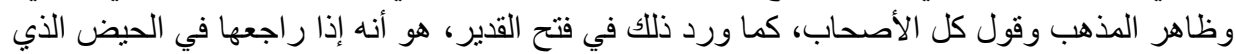

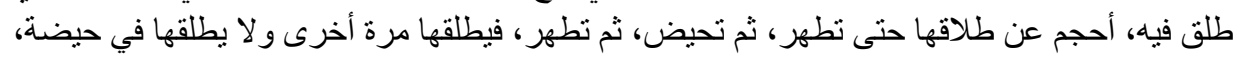
(4)

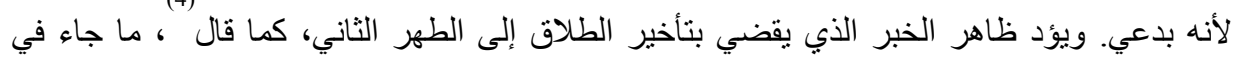

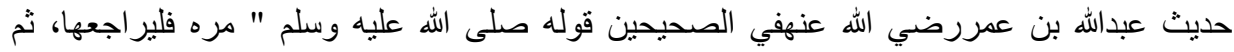
يمسكها حتى تطهر، ثم تحيض، ثم تطهر، ثم إن شاء أمسك بعد و إن شاء طلق قبل أن يمس، فتلألك العدة

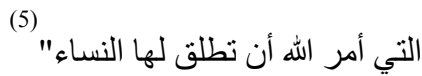

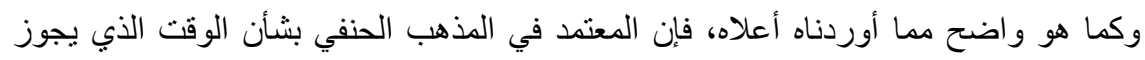

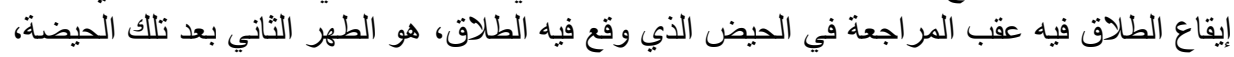
إستتادا إلى الرواية القاضية بتأجيل مباثرة الطلاق إلى الطهر الموالي الطي لطهر الحيضة التي حصل فيها

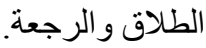

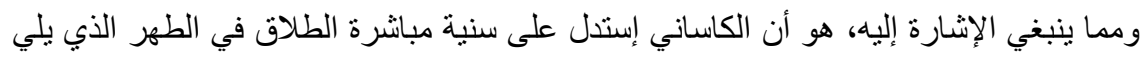

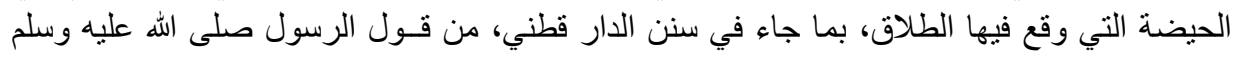

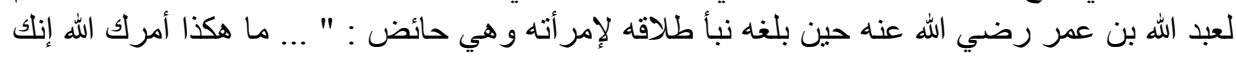
(6)

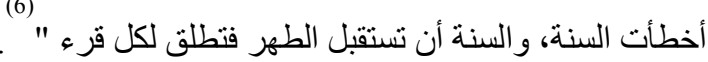

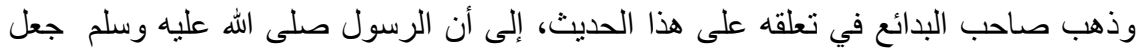

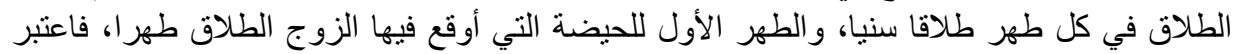

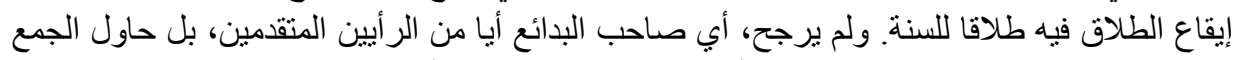

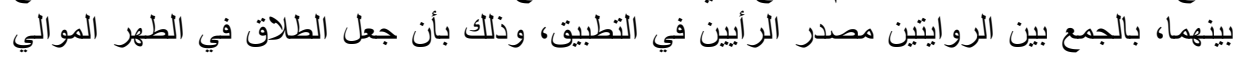

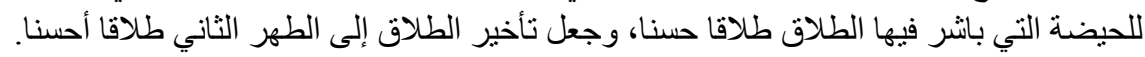
ثانيا : المالكية وقال المالكية : أن من طلق إمر أته وهي حائض وجبت عليه رجعتها، وكذلك الحال إن طلقها

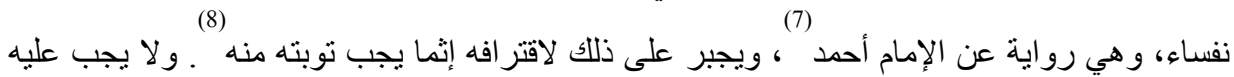
(9)

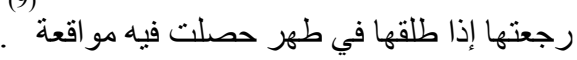
واختلفو ا في الوقت الذي يجبر فيه الزوج على ذلكة، فقال جمهور هم : يجبر طوال فترة العدة، 
وحجة المالكية فيما ذهبوا إليه، هي أن مدة العدة هي المدة المقررة شرعا لانفان العصام العلاقة

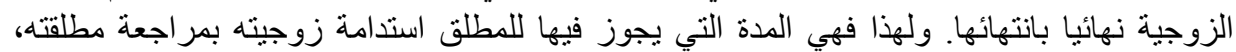
(11)

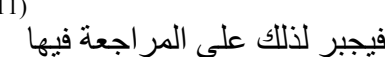

واختلفت الرواية عند أثشب، فنقل عنه البعض قوله بالإجبار في الحيضة التي حصل فيها

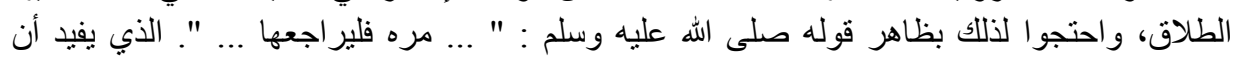

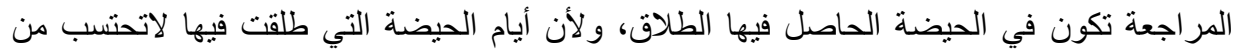
(12)

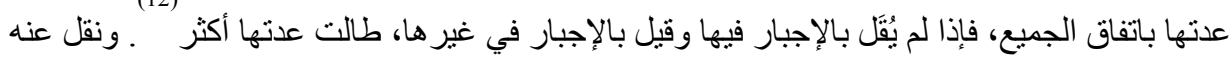
(13)

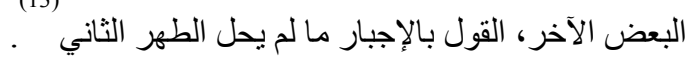

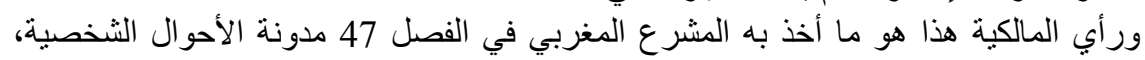

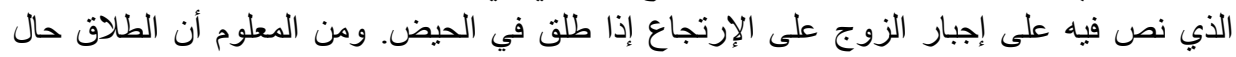

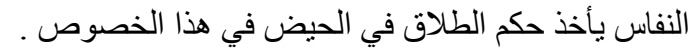

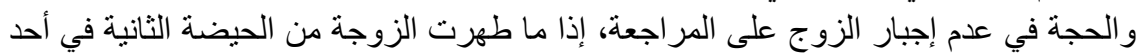

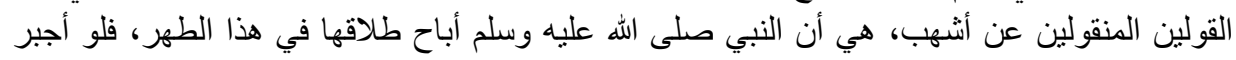

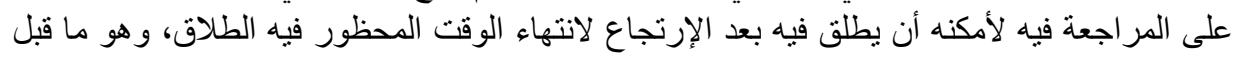
(14)

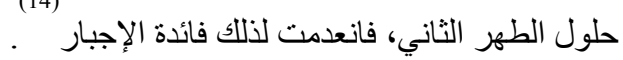
وقد رجح إبن المواز في هذه المسألة قول إين القاسم، وهو مذهب جمهور المالكية، على قول

و الظاهر أن سبب الرواية عن أشهب على النحو المتقدم، أي القول بالإجبار على المراجعة في

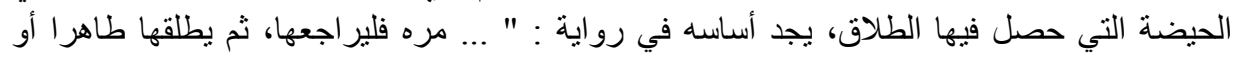

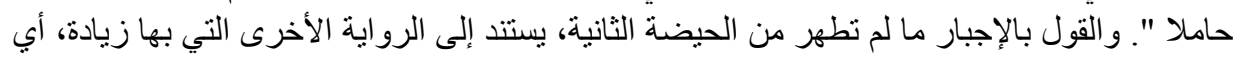

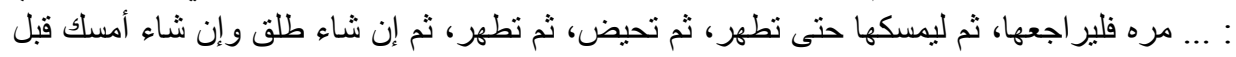

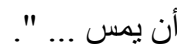

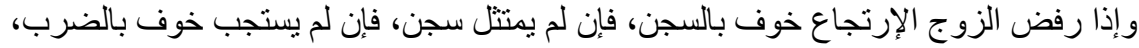

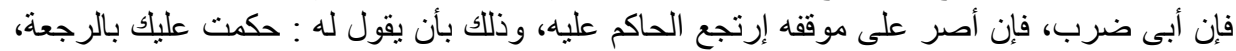

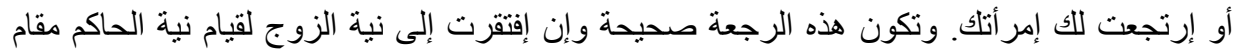

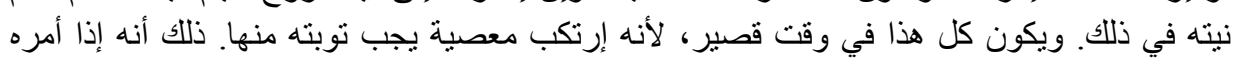

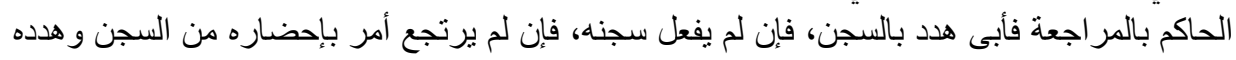
(16)

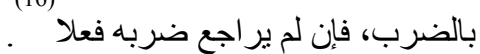

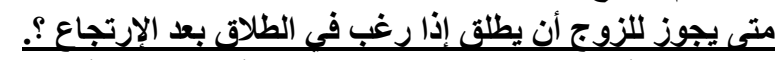

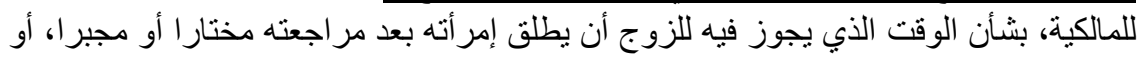

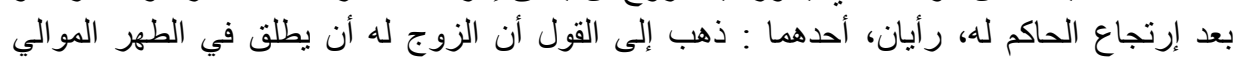

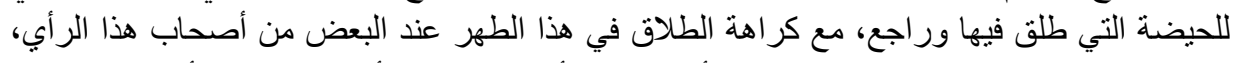

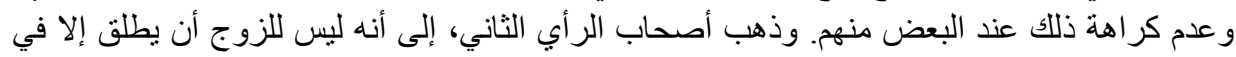
الطهر المو الي لطهر الحيضة التي طلق فيها وارتجع. 
إن تأخير الطلاق إلى الطهر الثاني، على هذا النحو، واجب عند بعض أصحاب هذا الرأي دون البعض الآخر منهم. وفي ما يلي تفصيل ذللك. البكان. الرأي الأول : يتفق أصحاب هذا الرأي على أنى أن للزوج بعد مر اجعة إمر أته المطلقة حال حيضها

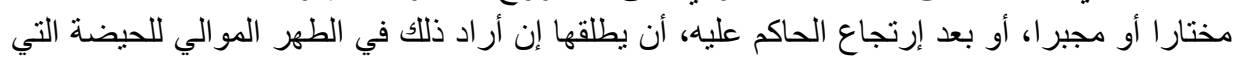

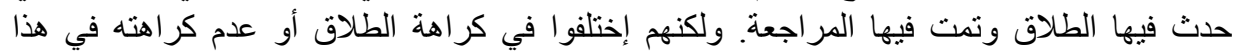

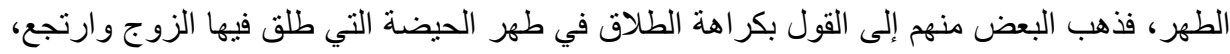

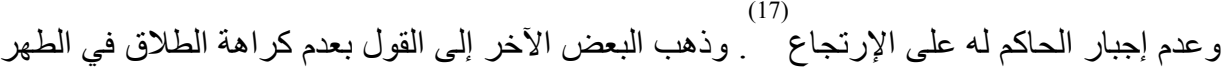

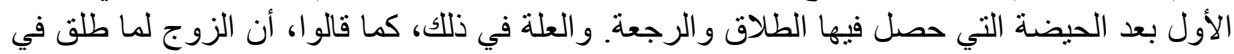

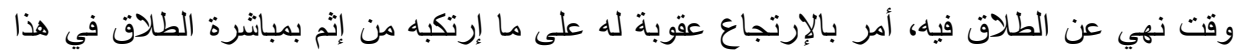
(18)

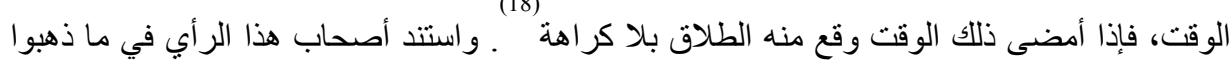

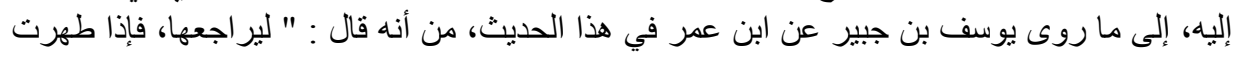
(19) فإن شاء فلبطلقها "

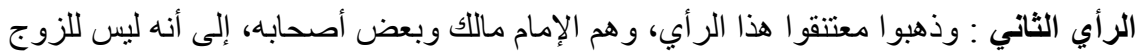

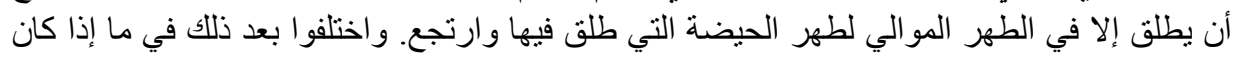

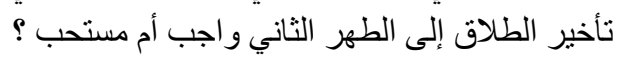
فذهب الإمام مالك وبعض أصحابه إلى القول بالوجوب. وذهب البعض من فقهاء المذهب إلى

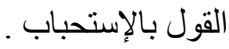
أما قول الإمام وبعض أصحابه بالوجوب، فيستفاد من النصبن التاليين :

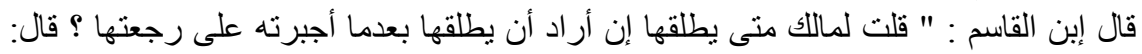

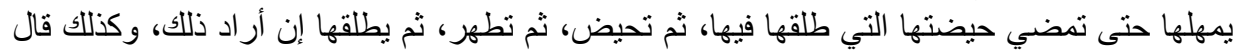
(20) وقال إبن قدامة : " وقال أصحاب مالك لايطلقها حتى تطهر، ثم تحيض، ثم تطهر، على ما جاء النبي صلى اله عليه وسلم " . في الحديث" (21) أي حديث عبداله بن عمر المتقدم والقاضي بتأخير الطلاق إلى الطهر الثاني.

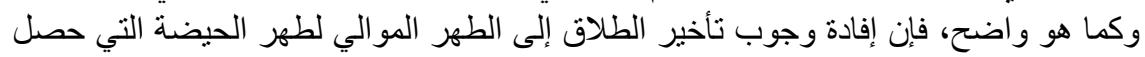

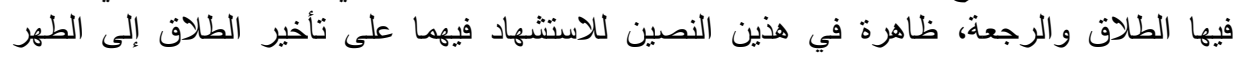

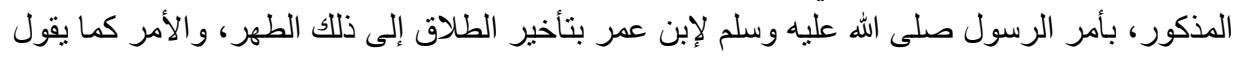
جمهور الأصوليون، يدل على الوجوب على ما لم تصرفه عن هذا المعنى قرينة دالة لألة على أحد معانيه

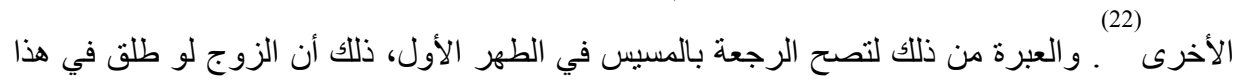

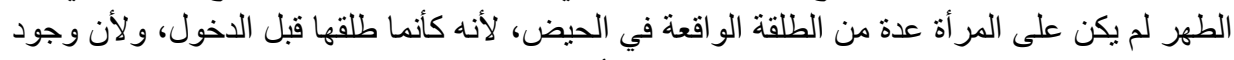

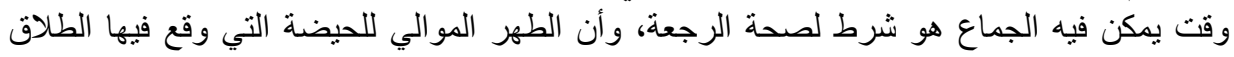
(23)

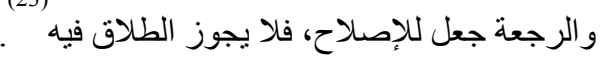
ولعل ما يؤيد وجوب تأخير الطلاق إلى الطهر الثاني، عند الإمام مالكك وبعض أصحابه، ما ذكره (24) ابن رشد في مقدمانه، إذ يقول : " و أمر [ أب الزوج ] أن يطلقها في الطهر الأول ... فالطهر الأول 
(25)

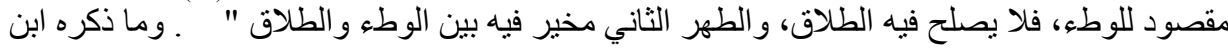

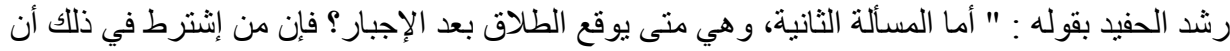

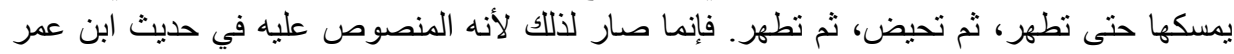

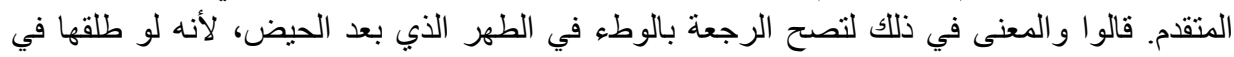
(26)

الطهر الذي بعد الحيضة لم يكن عليها من الطلاق الآخر عدة، لأنه كان يكون كالمطلق قبل الدخول " .

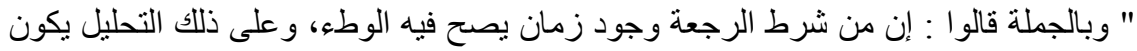

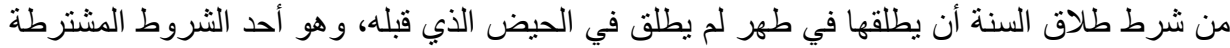
(27)

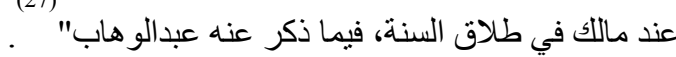

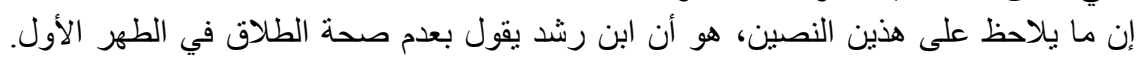

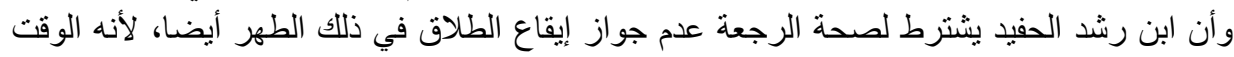

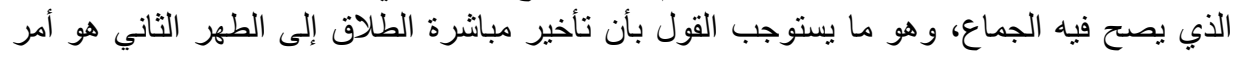
واجب .

ومما يجب ذكره في هذا المقام، هو أن أغلب ما وقع بين أيدينا للمالكية من مراجع لاتذكر إلا

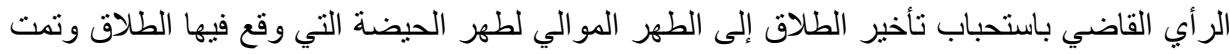
(28)

فيها المر اجعة، وأهملت حتى التلميح إلى الر أي القائل بوجوب تأخير الطلاق إلى الطهر الثاني .

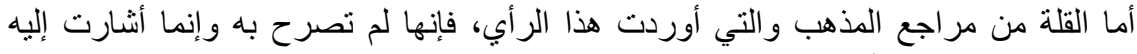

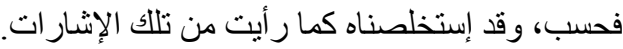

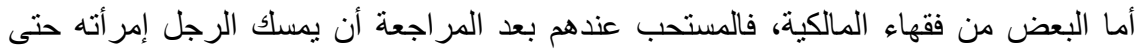

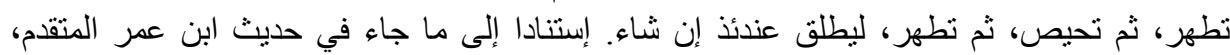
(29)

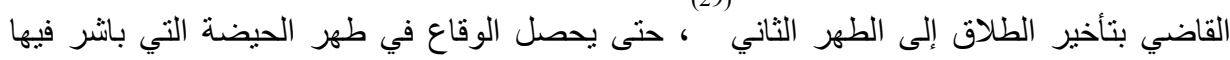

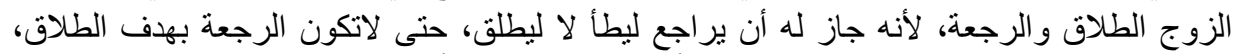

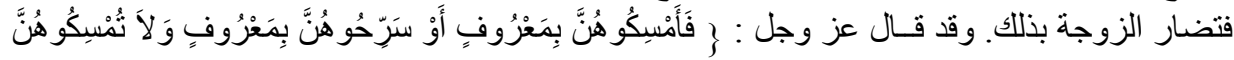

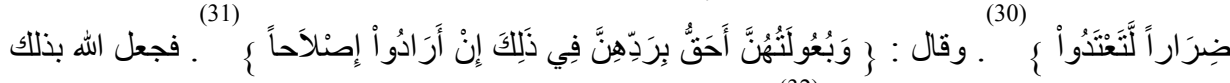

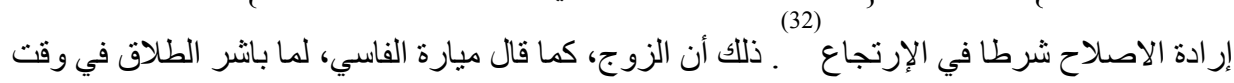

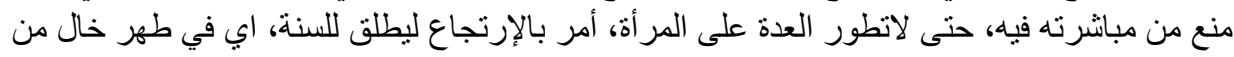

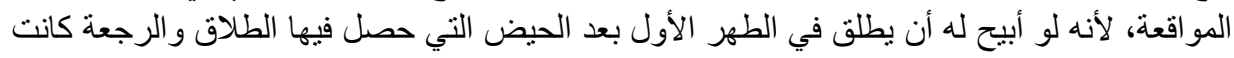

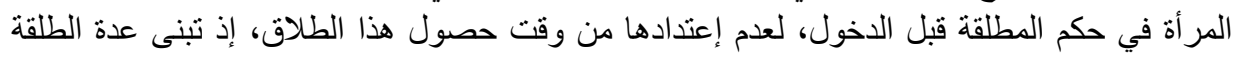

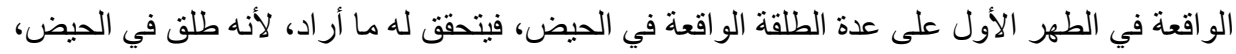

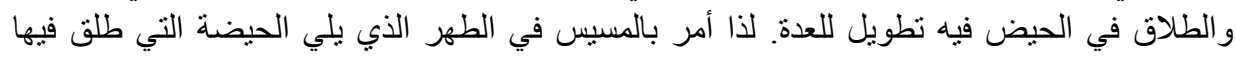

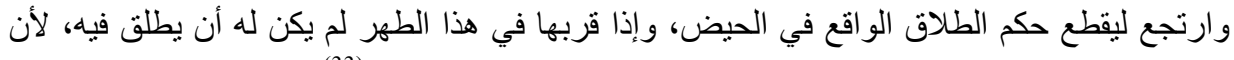
(33)

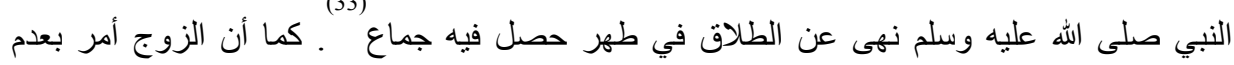

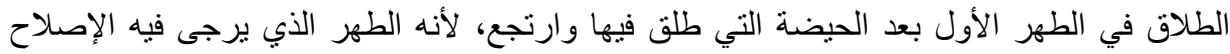

بالمو اقعة، ومنى حصلت المو افقة كره له الطلاق، فيمسكها حتى نطهر من حيضة أخرى (34). 
ويلاحظ أن ما ذكره الفاسي بشأن تطويل العدة على المطلقة لو سمح للارجل أن بطلق في الطهر

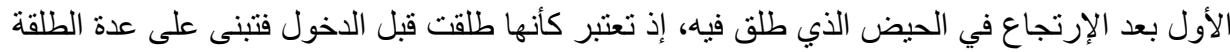

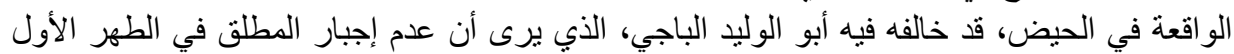

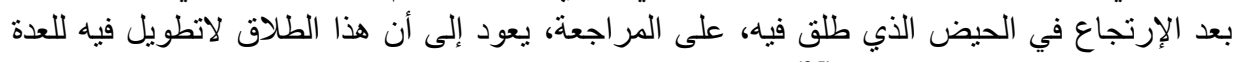
(35)

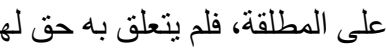

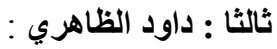

وذهب داود الظاهري إلى القول بوجوب المراجعة، لأن ظاهر الأمر في حديث عبداله ابن عمر (36)

يفيد الوجوب. و إذا رفض الزوج الإرنجاع أجبر عليه مطلقا، حسب ما ذكر صاحب البدائع ـ ـوذكر (37)

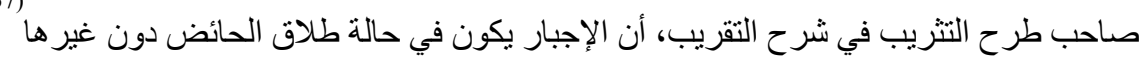

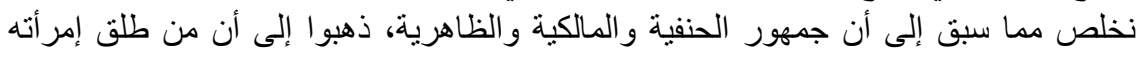

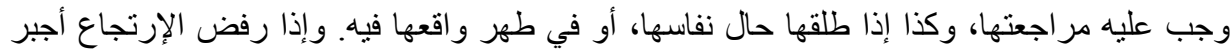

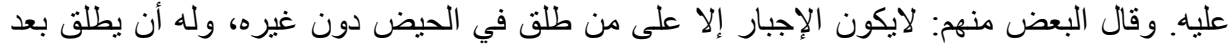

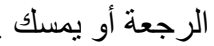

وقد إختلف أصحاب هذا الإتجاه في الوقت الذي يجوز فيه للزوج أن يطلق بعد المر اجعة، فقال

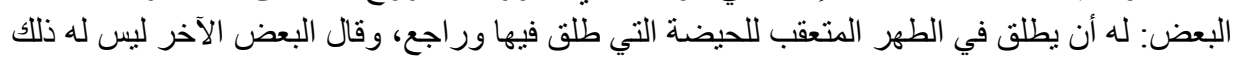

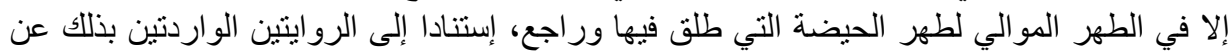

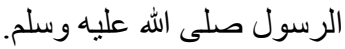

(1) - عبدالرحمن الجزيري : الفقه على الدذاهب الأربعة. دار إحياء التراث العربي. بيروت. لبنان ط2.

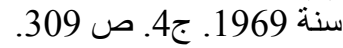

(2) - محمد بن عبد الرحمن بن عبدالرحيم المباركفوري : جامع الترمذي مع شرحه تحفة الأحوذي.

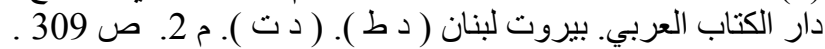

(3) - أبو عبدالله محمد البخاري : صحيح البخاري. دار الجيل. بيروت. لبنان. ( د ط ). ( د ت ) ـ م3.

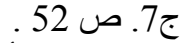
(4) - محمد أمين الثهير بإبن عابدين : حاثشية رد المختار على الدر المختار. شرح تتوير الأبصار.

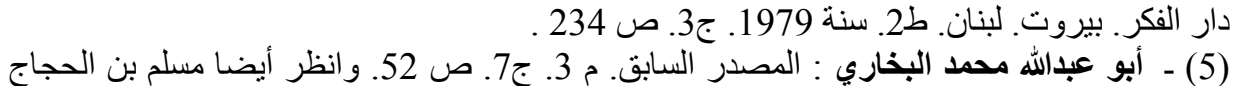

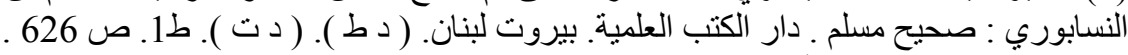

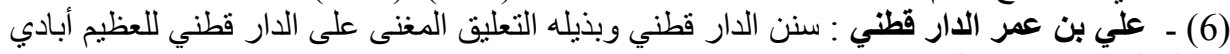

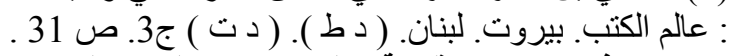

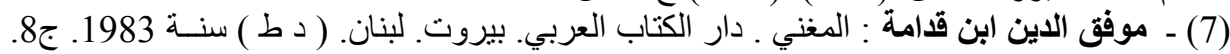

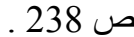

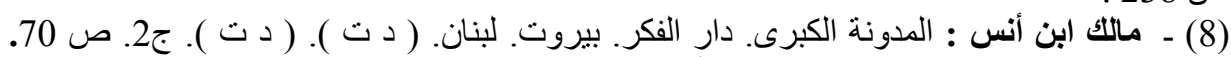

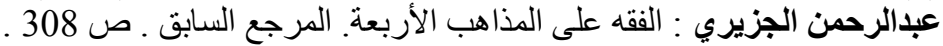

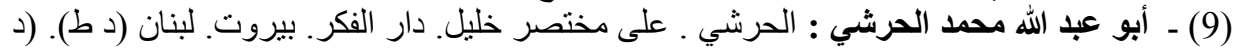


(11) - سليمان بن خلف بن سعد الباجي : المنتقى شرح موطأ الإمام مالك. دار الكتاب العربي.

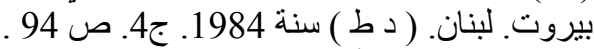

(12) - محمد بن أحمد بن محمد بن رشد الثهير بان بابن رشد الحفيد : بداية المجتهد ونهاية المقتصد.

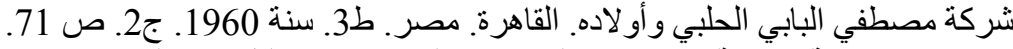

(13) - عبد الباقي الزرقاني : شرح الزرقاني على مختصر خليل. دار الفكر. بيروت. لبن لبنـان ـ ( د ط ).

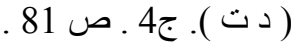

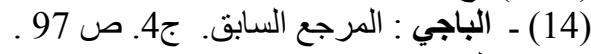

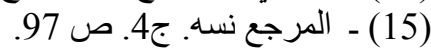

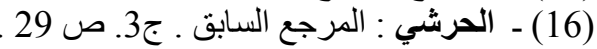

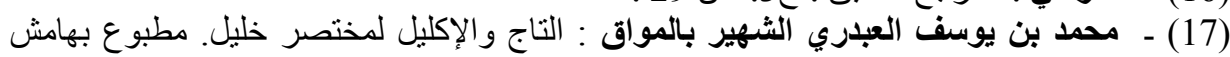

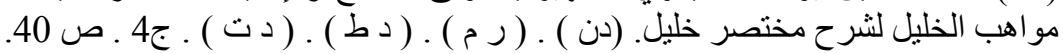

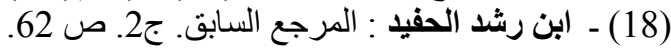

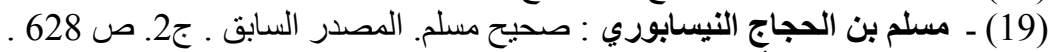

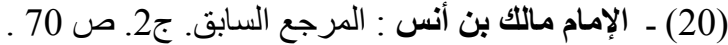

(21) - شمس الاين بن قدامة : الثران الثرح الكبير على متن المقنع مطبوع مع المغني. دار الكتاب العربي.

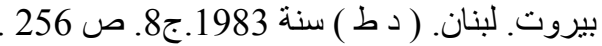

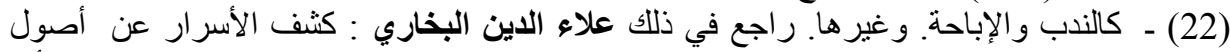

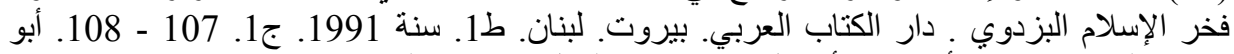

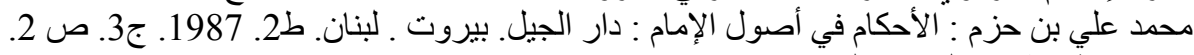

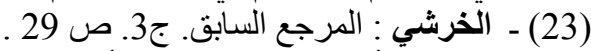
(24) - الصواب الا بطلقها في الطهر الأول. و التصويب من السياق .

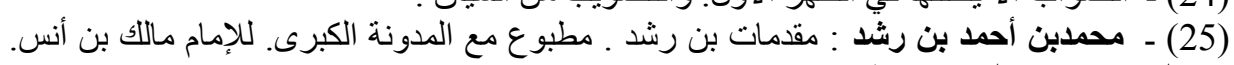

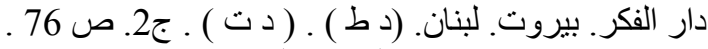

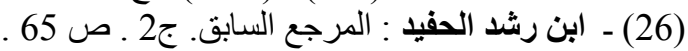

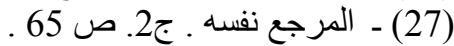

(28) - محمد بن محمد الحطاب : مواهب الجليل لثرح مختصر خليل. ( د ن ). ( د م ). ط2. 1978.

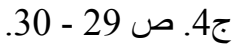

(29) - محمد عليش : شرح منح الجليل على مختصر خليل. دار الفكر. بيروت. لبنـان. ط1. 1984. ج4. ص - 37 - 38 - 38 .

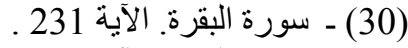

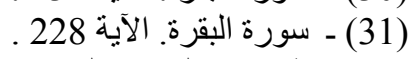

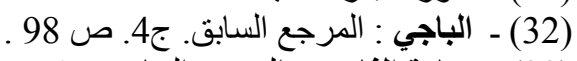

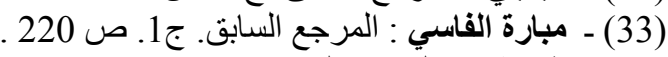

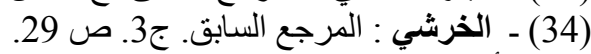

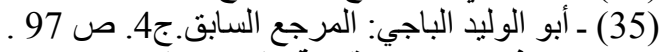

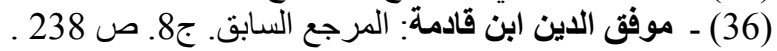

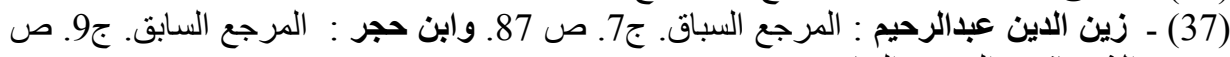
288. والثوكاني : المرجع السابق. ج6. ص ص 223. 